Barry E. Gidal, PharmD

Robert T. Wechsler, MD, $\mathrm{PhD}$

Raman Sankar, MD, PhD Georgia D. Montouris, MD

H. Steve White, PhD James C. Cloyd, PharmD Mary Clare Kane, PhD Guangbin Peng, MS

David M. Tworek, MS, MBA

Vivienne Shen, MD, PhD Jouko Isojarvi, MD, PhD

Correspondence to Dr. Gidal:

barry.gidal@wisc.edu
Supplemental data at Neurology.org

\section{Deconstructing tolerance with clobazam}

\section{Post hoc analyses from an open-label extension study}

\section{OPEN}

\section{ABSTRACT}

Objective: To evaluate potential development of tolerance to adjunctive clobazam in patients with Lennox-Gastaut syndrome.

Methods: Eligible patients enrolled in open-label extension study OV-1004, which continued until clobazam was commercially available in the United States or for a maximum of 2 years outside the United States. Enrolled patients started at $0.5 \mathrm{mg} \cdot \mathrm{kg}^{-1} \cdot \mathrm{d}^{-1}$ clobazam, not to exceed $40 \mathrm{mg} / \mathrm{d}$. After 48 hours, dosages could be adjusted up to $2.0 \mathrm{mg} \cdot \mathrm{kg}^{-1} \cdot \mathrm{d}^{-1}$ (maximum $80 \mathrm{mg} / \mathrm{d}$ ) on the basis of efficacy and tolerability. Post hoc analyses evaluated mean dosages and dropseizure rates for the first 2 years of the open-label extension based on responder categories and baseline seizure quartiles in OV-1012. Individual patient listings were reviewed for dosage increases $\geq 40 \%$ and increasing seizure rates.

Results: Data from 200 patients were included. For patients free of drop seizures, there was no notable change in dosage over 24 months. For responder groups still exhibiting drop seizures, dosages were increased. Weekly drop-seizure rates for $100 \%$ and $\geq 75 \%$ responders demonstrated a consistent response over time. Few patients had a dosage increase $\geq 40 \%$ associated with an increase in seizure rates.

Conclusions: Two-year findings suggest that the majority of patients do not develop tolerance to the antiseizure actions of clobazam. Observed dosage increases may reflect best efforts to achieve seizure freedom. It is possible that the clinical development of tolerance to clobazam has been overstated.

ClinicalTrials.gov identifier: NCT00518713 and NCT01160770.

Classification of evidence: This study provides Class III evidence that the majority of patients do not develop tolerance to clobazam over 2 years of treatment. Neurology ${ }^{\circledR} 2016 ; 87: 1806-1812$

\section{GLOSSARY}

AED = antiepileptic drug; GABA = $\gamma$-aminobutyric acid; LGS = Lennox-Gastaut syndrome; OLE = open-label extension.

The pharmacology and pharmacokinetics of available antiepileptic drugs (AEDs) can complicate epilepsy treatment. One concern is tolerance, a loss of drug efficacy after repeated administration, leading to subsequent dosage increases. Tolerance may be an adaptive mechanism following long-term drug exposure. ${ }^{1-3}$

Tolerance to antiepileptic effects has been suggested for a variety of AEDs, ${ }^{4,5}$ most commonly benzodiazepines, ${ }^{6,7}$ with variable and unpredictable timing that limits their clinical use. ${ }^{2,7}$ One putative mechanism of benzodiazepine tolerance is downregulation of $\gamma$-aminobutyric acid (GABA) receptors following prolonged exposure; however, tolerance has been observed in the absence of receptor changes, and evidence has been mixed. ${ }^{8-10}$ While there is substantial

\footnotetext{
From the School of Pharmacy and Department of Neurology (B.E.G.), University of Wisconsin, Madison; Idaho Comprehensive Epilepsy Center (R.T.W.), Boise; David Geffen School of Medicine at UCLA (R.S.), University of California-Los Angeles; School of Medicine (G.D.M.), Boston University, MA; School of Pharmacy (H.S.W.), University of Washington, Seattle; Center for Orphan Drug Research (J.C.C.), College of Pharmacy, University of Minnesota, Minneapolis; Prescott Medical Communications Group (M.C.K.), Chicago, IL; and Lundbeck LLC (G.P., D.M.T., V.S., J.I.), Deerfield, IL.

Go to Neurology.org for full disclosures. Funding information and disclosures deemed relevant by the authors, if any, are provided at the end of the article. The Article Processing Charge was paid by Lundbeck, LLC.

This is an open access article distributed under the terms of the Creative Commons Attribution-NonCommercial-NoDerivatives License 4.0 (CC BY-NC-ND), which permits downloading and sharing the work provided it is properly cited. The work cannot be changed in any way or used commercially.
} 
evidence from preclinical animal models demonstrating the development of tolerance, ${ }^{11-15}$ extrapolation of these observations to the clinical setting is not straightforward. Differences in experimental design, seizure model, and species selection may contribute to variability between studies and may limit extrapolation to humans. ${ }^{2}$ Moreover, it is possible that human patients do not exhibit tolerance to benzodiazepines at the same rates observed in laboratory animals. Whether tolerance actually occurs in patients is a clinically important question in the long-term treatment of epilepsy.

There is a paucity of contemporary, controlled clinical trials with well-defined criteria and outcome measures that would resolve this issue. Tolerance with resultant loss of clinical effect may not occur in all patients; therefore, analysis of individual response, a feature lacking in many earlier studies, is also critical. Furthermore, it is possible that benzodiazepines with differing chemical structures or receptor affinities may display differing patterns of tolerance, should it exist. The objective of the present study was to construct a rigorous analysis of clobazam (ONFI, Lundbeck, Deerfield, IL), a 1,5-benzodiazepine indicated in the United States for the adjunctive treatment of seizures associated with Lennox-Gastaut syndrome (LGS) in patients $\geq 2$ years of age, ${ }^{16}$ in a welldefined population of patients derived from prospective, randomized, controlled clinical trials.

METHODS These post hoc analyses used data collected during a phase 3 lead-in study, OV-1012, ${ }^{17}$ and an open-label extension (OLE) study, OV-1004. ${ }^{18}$ To examine tolerance, we used 3 analytic approaches: group mean changes in seizure rates and dosage based on responder categories, group mean changes in seizure rates and dosage as a function of baseline seizure frequency because baseline seizure frequency may affect the development of tolerance, and individual mean changes in seizure rates and dosage because group analysis may obscure changes occurring in only a subset of patients.

Patients. Patients were eligible to participate in the lead-in study (OV-1012) if they were between 2 and 60 years of age with a diagnosis of LGS (onset $<11$ years of age), weighed $\geq 12.5 \mathrm{~kg}$, and received stable dosages of 1 to 3 AEDs (except benzodiazepines) for $\geq 30$ days. Patients who met the following criteria were eligible to enroll in the OLE study (OV-1004): completion of lead-in study OV-1002 ${ }^{19}$ (data not used in these analyses) or OV-1012; <14 days since the last dose of study drug in lead-in study; no adverse events or serious adverse events probably or definitely related to clobazam as judged by the investigator; and receipt of $\leq 3$ concomitant AEDs, including vagus nerve stimulation and ketogenic diet. However, receipt of
$>3$ concomitant AEDs was permitted after enrollment in the OLE.

Standard protocol approvals, registrations, and patient consents. Both the lead-in study (NCT00518713) and OLE study (NCT01160770) were approved by an independent ethics committee or institutional review board at each study site, and each patient (or parent/caregiver) provided written informed consent.

Study design. The lead-in OV-1012 was a multicenter, randomized, double-blind, placebo-controlled, parallel-group study. It comprised a 4-week baseline period, a 3-week titration period, and a 12 -week maintenance period. The OLE study continued until clobazam (dosing described below) was commercially available in the United States (maximum 6 years) or for a maximum of 2 years outside the United States.

Dosing. During the OLE, clobazam was administered twice daily. Enrolled patients $(n=267)$ were started at $0.5 \mathrm{mg} \cdot \mathrm{kg}^{-1} \cdot \mathrm{d}^{-1}$, not to exceed $40 \mathrm{mg} / \mathrm{d}$. This dosage was maintained for 48 hours; then dosages could be adjusted up to $2.0 \mathrm{mg} \cdot \mathrm{kg}^{-1} \cdot \mathrm{d}^{-1}$ (maximum allowed dosage $80 \mathrm{mg} / \mathrm{d}$ ) on the basis of efficacy and tolerability. To optimize patient care, investigators were allowed to start, adjust, or discontinue other seizure treatments, including vagus nerve stimulation and ketogenic diet.

Analyses. Three separate post hoc analyses were conducted to examine tolerance.

Responder rates. Changes in weight-adjusted mean dosages (milligram per kilogram per day) were evaluated over the first 2 years of the OLE trial on the basis of patient responder categories in lead-in study OV-1012 (100\%, $\geq 75 \%, 50 \%-<75 \%, 25 \%-<$ $50 \%$, or $<25 \%$ reduction in weekly drop-seizure rates vs baseline). Mean weekly drop-seizure rates over 24 months were examined in patients with $100 \%$ or $\geq 75 \%$ reductions during the lead-in study.

Baseline seizure quartiles. In a second analysis, changes in weight-adjusted mean dosages (milligram per kilogram per day) by baseline seizure quartiles in lead-in study OV-1012 $(<10,10$ $31,32-110$, or $111-1,147$ drop seizures/wk at baseline) were examined. Mean weekly drop-seizure rates over 24 months also were examined in patients on the basis of baseline seizure quartiles during OV-1012.

Individual patients. Finally, individual patient listings were reviewed for evidence of dosage increases $\geq 40 \%$ (based on weightadjusted dosages [milligram per kilogram per day]) and for a loss of response based on seizure rates at the end of the follow-up period (i.e., $100 \%$ responders at the end of OV-1012 but not seizure free at the 24-month mark of OV-1004, $75 \%$ responders with a seizure reduction $<75 \%, 50 \%$ responders with a seizure reduction $<50 \%$ ). A dosage increase of $\geq 40 \%$ plus loss of response was defined as tolerance for individual patients.

Classification of evidence. This post hoc analysis of data from a lead-in and an OLE study provides Class III evidence that the risk of developing tolerance to clobazam was low over the 2 years of treatment observed here.

RESULTS Responder rates. Responder rate data from OV-1012 were available for 200 patients, who therefore were included in the post hoc analyses. There was no notable change in dosage over 24 months for patients who were free from drop seizures (figure 1). All other drop-seizure responder groups (i.e., $\geq 75 \%$, $50 \%-<75 \%, 25 \%-<50 \%,<25 \%)$ had notable 


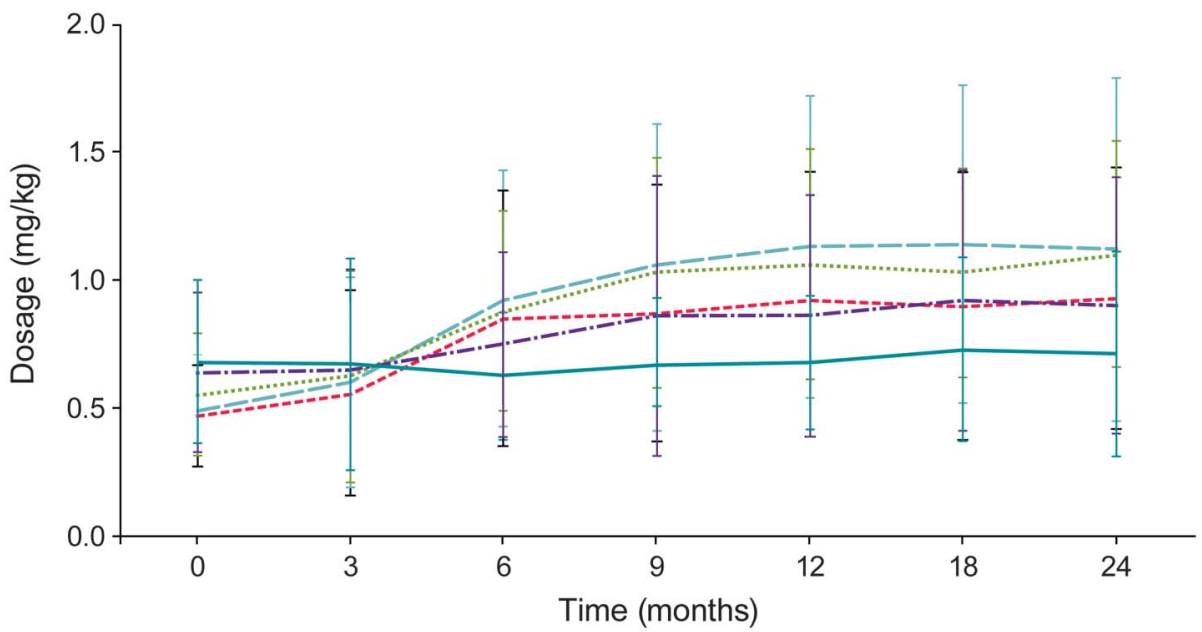

Responders

$\begin{array}{ll}--<25 \% & 65 \\ ----25 \% \text { to }<50 \% & 33 \\ \cdots \cdots . . .50 \% \text { to }<75 \% & 38 \\ -\cdot-. \geq 75 \% & 64 \\ -100 \% & 20\end{array}$

Patients ( $n$ )

$\begin{array}{ll}62 & 56 \\ 31 & 30 \\ 38 & 38 \\ 64 & 61 \\ 20 & 19\end{array}$

$\begin{array}{llll}55 & 47 & 44 & 40 \\ 29 & 28 & 27 & 25 \\ 36 & 35 & 32 & 31 \\ 56 & 57 & 55 & 51 \\ 18 & 18 & 17 & 17\end{array}$

OLE is OV-1004 (NCT01160770). ${ }^{18}$ Lead-in refers to study OV-1012 (NCT00518713). ${ }^{17}$

increases in dosage over time (figure 1). Most increases were observed during the first 9 to 12 months; dosages remained relatively stable thereafter until the end of follow-up (24 months). Weekly drop-seizure rates for the $100 \%$ and $\geq 75 \%$ responder groups demonstrated a consistent response over time (figure 2).

Baseline seizure quartiles. When analyzed by baseline seizure quartiles, patients who experienced $<10$ weekly seizures at baseline had the least change in dosage over time (figure 3). Mean dosages by baseline seizure quartiles showed that patients in the second, third, and fourth quartiles had progressively greater increases in dosage over time (figure 3). However, patients had consistent mean weekly drop-seizure frequencies without a notable increase in seizures over the course of the 24-month analysis (figure 4).

Individual patient response. Individual patient data were reviewed for dosage increases $\geq 40 \%$ Figure 2 Mean weekly drop seizures in open-label extension (OLE) study for $100 \%$ and $\geq 75 \%$ responders in
lead-in study

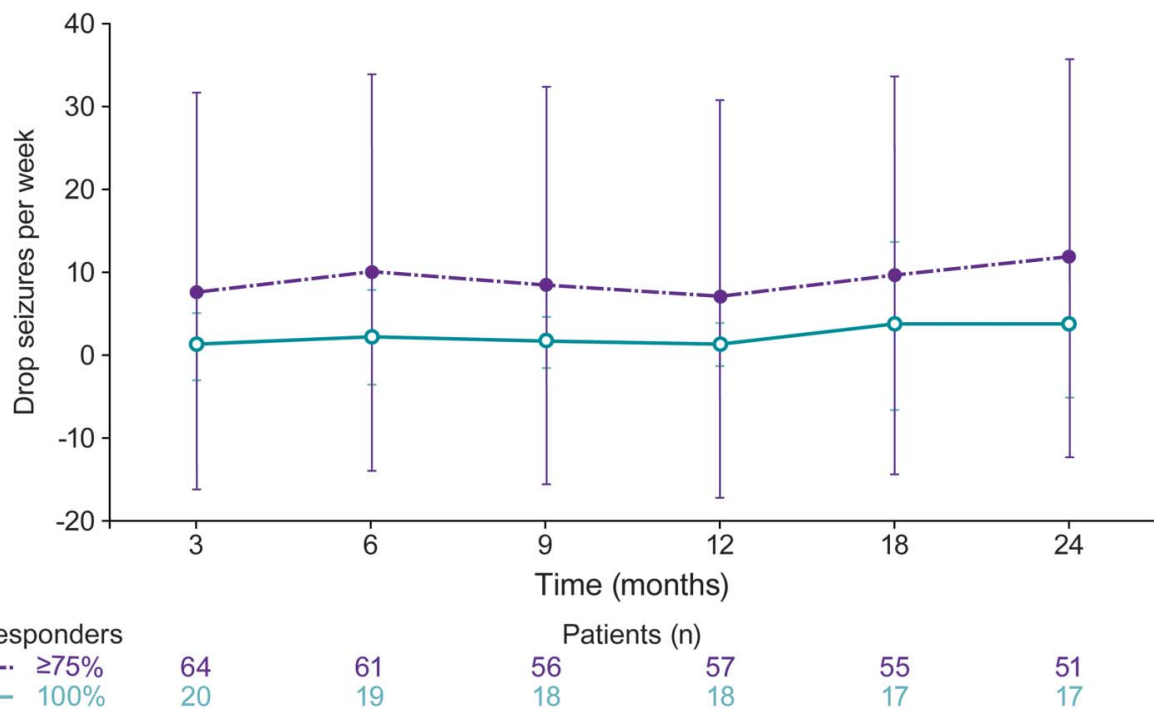

OLE is OV-1004 (NCT01160770). ${ }^{18}$ Lead-in refers to study OV-1012 (NCT00518713). ${ }^{17}$ 


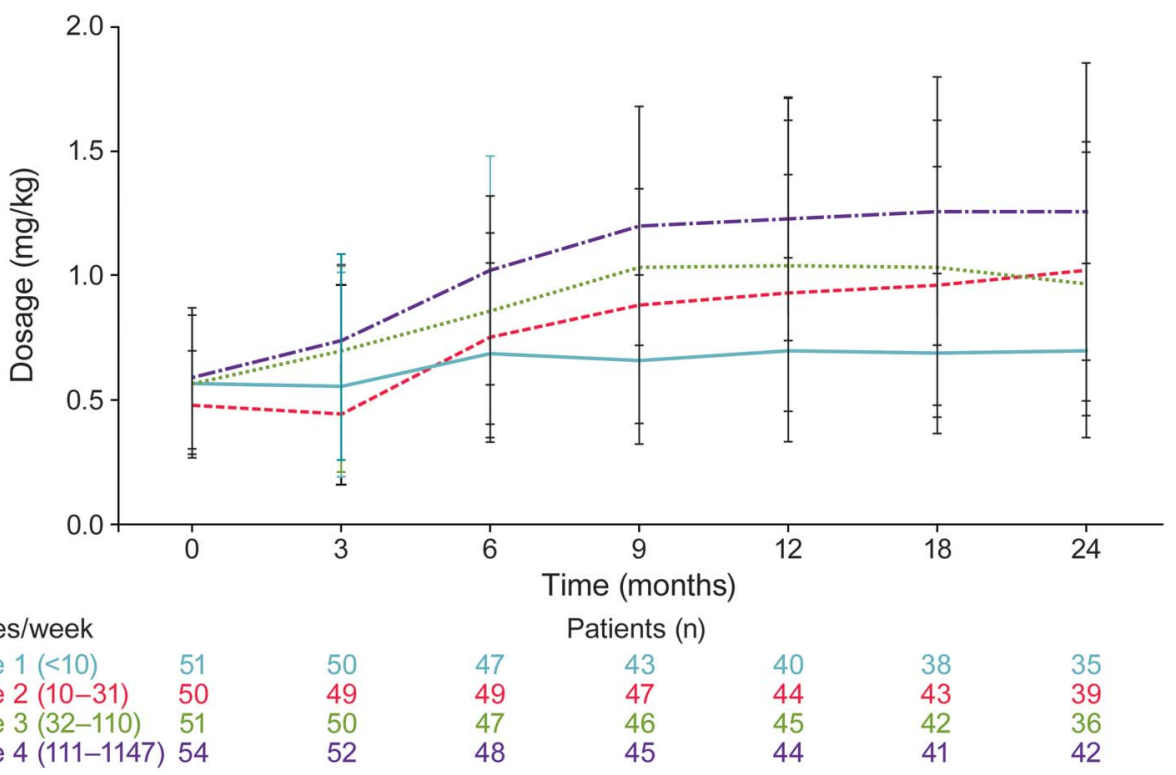

Drop seizures/week

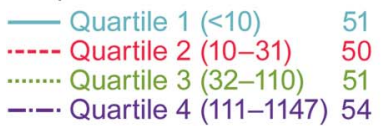

50

48

OLE is OV-1004 (NCT01160770). ${ }^{18}$ Lead-in refers to study OV-1012 (NCT00518713). ${ }^{17}$

correlated with decreased seizure control, as measured by change in responder category (e.g., the return of drop seizures in patients who had previously been free of drop seizures). This was found in a minority of patients (table 1). Individual patient results are presented in table e-1 at Neurology.org.
DISCUSSION It is well recognized that the complex pharmacology and pharmacokinetics of the available AEDs can confound the treatment of epilepsy. Among the many uncertainties that clinicians face when selecting an AED, it is possible that an initially robust clinical response to a treatment will diminish over time. In other words, pharmacodynamic

Figure 4 Mean frequency of weekly drop seizures in open-label extension (OLE) study based on baseline seizure quartile in lead-in study

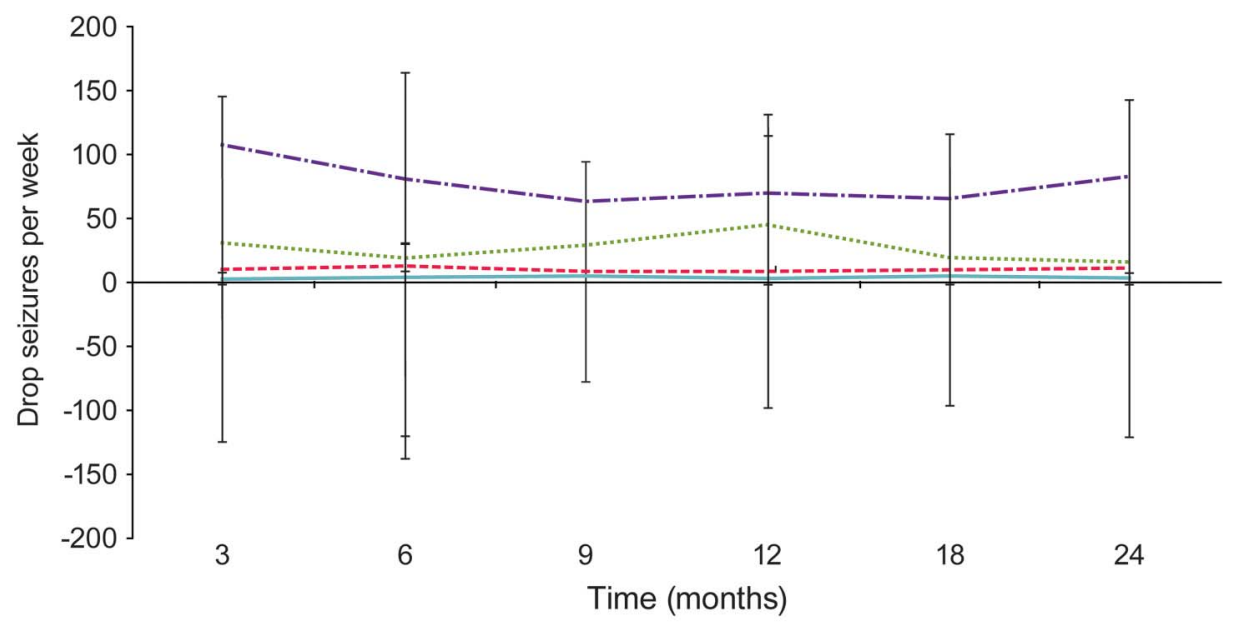

Drop seizures/week

— Quartile $1(<10)$

----- Quartile $2(10-31)$

- Quartile 2 (10-31)

-.-. Quartile 4 (111-1147) 52

$\begin{array}{ll}50 & 47 \\ 49 & 49 \\ 50 & 47 \\ 52 & 48\end{array}$

Patients (n)

OLE is OV-1004 (NCT01160770). ${ }^{18}$ Lead-in refers to study OV-1012 (NCT00518713). ${ }^{17}$ 


\begin{tabular}{|c|c|c|c|}
\hline Table 1 & \multicolumn{3}{|c|}{$\begin{array}{l}\text { Tolerance }{ }^{a} \text { rates based on review of individual patient dosages and } \\
\text { seizure rates }\end{array}$} \\
\hline \multicolumn{2}{|c|}{ Responder group } & $\begin{array}{l}\geq 40 \% \text { dosage } \\
\text { increase, } N\end{array}$ & $\begin{array}{l}\geq 40 \% \text { dosage increase } \\
+ \text { loss of response, } n(\%)\end{array}$ \\
\hline \multicolumn{2}{|l|}{ Total } & 85 & 10 (11.8) \\
\hline \multicolumn{2}{|c|}{$100 \%$ responders } & 18 & $1(5.6)$ \\
\hline \multicolumn{2}{|c|}{$\geq 75 \%$ responders } & 41 & $7(17.1)$ \\
\hline \multicolumn{2}{|c|}{$50 \%-<75 \%$ responders } & 26 & $2(7.7)$ \\
\hline
\end{tabular}

a Tolerance was defined as a $\geq 40 \%$ increase in dosage coincident with an increase in seizures. tolerance developed within 1 to 6 months of continuous benzodiazepine therapy. In the present analysis, seizure rates were consistent for groups on the basis of responder categories and baseline seizure quartiles, indicating no loss of response over 2 years of clobazam treatment. Mean dosage increases observed during the first 12 months seem to reflect best practices in an effort to achieve the clinical goal of seizure freedom rather than tolerance to clobazam treatment. In addition to group analysis, review of individual patient dosages and seizure rates indicated that the vast majority of patients did not develop tolerance to clobazam. A noticeable drop in patient retention rates was observed between 2 and 3 years, but this drop was driven by sites outside the United States where patients were able to remain in the study for only 2 years. ${ }^{25}$ Because the majority of patients were allowed to remain in the OLE trial for 2 years, the time frame of this analysis was adequate to evaluate the potential onset of tolerance with long-term clobazam administration.

While our data suggest that tolerance to clobazam in patients with LGS does not appear to be a common occurrence, one should be cautious in extrapolating these findings to the entire benzodiazepine class. For example, a comparison of real-world use of clobazam and clonazepam in patients with epilepsy in the United Kingdom showed that median clonazepam dosages increased by $25 \%$ and $50 \%$ for adults and children, respectively, while median clobazam dosages did not change from baseline to the last followup (adults, 5.2-5.5 years; children, 5.5-6.3 years) ${ }^{26}$ It is also important to note that clobazam is structurally different from classic benzodiazepines: the 2 nitrogen components at the core of all benzodiazepines have a 1,5 configuration in clobazam compared to a 1,4 configuration in the classic benzodiazepines (e.g., diazepam, lorazepam, and clonazepam). Clobazam and its active $N$-desmethyl metabolite also appear to display significantly greater binding affinity to the $\alpha 2$ vs $\alpha 1$ subunit of the GABA-A receptor. This apparent pattern of binding selectivity differentiates this agent from other classic benzodiazepines such as clonazepam. ${ }^{27}$ These properties may allow clobazam to retain efficacy as antiepileptic agent while displaying a relatively low risk for the development of tolerance with long-term treatment. ${ }^{17-19}$

Our analysis was not designed to address the issue of tolerance (or lack thereof) to adverse events associated with clobazam treatment. This is an interesting yet mechanistically different question. Bateson ${ }^{1}$ theorized that distinct mechanisms may underlie different therapeutic effects and tolerance seen with benzodiazepine treatment based on the differing time courses of these effects. For example, tolerance to the sedative effect occurs more rapidly than tolerance to the antiseizure effect, and tolerance to the anxiolytic 
effect occurs slowly. Bateson ${ }^{1}$ suggested that prolonged agonism at the GABA receptor leads to desensitization that finally results in uncoupling, a mechanism that could account for the differential time course of effects.

Clearly, the potential for any patient to develop tolerance to an AED is an important clinical concern. Although diminished therapeutic response appears to be infrequent, this analysis demonstrates that, whether a result of pharmacologic tolerance or evolving disease state, it can still occur in some patients. Indeed, although loss of efficacy over time (i.e., tolerance) is most commonly associated with benzodiazepine treatment, it also has been noted clinically with other structurally and mechanistically diverse AEDs. ${ }^{4,5}$ Unfortunately, no predictive factors that might lead to eventual pharmacologic tolerance were identified. Future investigations directed toward more detailed individual patient analysis, likely at the genomic level, are certainly warranted. Because of the impracticality of a longitudinal, monotherapy analysis in this patient population, the methodology used here may provide unique insights into the potential development of tolerance to clobazam in the clinical setting. For now, our observations suggest that the development of clinical tolerance to clobazam may be overstated and that this agent may provide a valuable long-term option for patients with LGS.

\section{AUTHOR CONTRIBUTIONS}

B.E. Gidal was responsible for study concept and design, data interpretation, and drafting the manuscript. R.T. Wechsler, R. Sankar, G. Montouris, H.S. White, and J.C. Cloyd were responsible for analysis and interpretation of data and editing of the manuscript. M. Kane was responsible for drafting and editing of the manuscript, including creating tables and figures, incorporating all author comments, and formatting the manuscript for submission. G. Peng, D.M. Tworek, V. Shen, and J. Isojarvi were responsible for analysis and interpretation of data and editing of the manuscript. All authors have approved the final manuscript for submission.

\section{STUDY FUNDING}

Funding for this project and for original clinical trials was provided by Lundbeck LLC, Deerfield, IL.

\section{DISCLOSURE}

B. Gidal has received honoraria for speaking engagements from UCB, Eisai, and Sunovion and for consulting from UCV, Eisai, Sunovion, Upsher-Smith, Lundbeck, and SK-Bioscience. R. Wechsler has participated in clinical trials for Alexza, Eisai, GW, Lundbeck, Marinus, SK Life Science, Sunovion, UCB, Upsher-Smith, and Vertex; has provided consulting services and/or participated in scientific advisory boards for Eisai, GW, Lundbeck, Sunovion, UCB, and Upsher-Smith; and has received honoraria for speaking engagements from Eisai, Cyberonics, Lundbeck, Sunovion, and UCB. R. Sankar has received grants or research support from NIH/National Institute of Neurological Disorders and Stroke, Pfizer, and Acorda; has received honoraria or consultation fees from UCB, Lundbeck, Supernus, Upsher-Smith, Eisai, and Cyberonics; and has participated in speakers' bureaus for UCB, Lundbeck, Supernus, Eisai, and Cyberonics. G. Montouris has served on scientific advisory boards for Acorda Therapeutics, Upsher Smith, and Lundbeck and is a member of the Expert Panel UCB Pregnancy Registry. H. White has received consulting honoraria from Upsher-Smith, Lundbeck, and Takeda; has received grant support from the National Institute of Neurological
Disorders and Stroke and NIH; has received other support from Citizens United for Research in Epilepsy; and is a scientific cofounder of NeuroAdjuvants, Inc, Salt Lake City, UT. J. Cloyd has received grant support from NIH/National Institute of Neurological Disorders and Stroke, Citizens United for Research in Epilepsy, the Epilepsy Foundation, the American Epilepsy Society, Paralyzed Veterans of American, Pfizer, and Genzyme; has received royalties from Ligand Pharmaceuticals; and has served as a consultant for Upsher Smith Laboratories, UCB, Lundbeck, Eisai, Epalex, and Xeris Pharmaceuticals. M. Kane is an employee of Prescott Medical Communications Group, Chicago, IL. G. Peng and J. Isojarvi were employees of Lundbeck LLC, Deerfield, IL, at the time the analyses were conducted. D. Tworek and V. Shen are employees of Lundbeck LLC, Deerfield, IL. Go to Neurology.org for full disclosures.

Received January 22, 2016. Accepted in final form July 11, 2016.

\section{REFERENCES}

1. Bateson AN. Basic pharmacologic mechanisms involved in benzodiazepine tolerance and withdrawal. Curr Pharm Des 2002;8:5-21.

2. Loscher W, Schmidt D. Experimental and clinical evidence for loss of effect (tolerance) during prolonged treatment with antiepileptic drugs. Epilepsia 2006;47:1253-1284.

3. Vinkers $\mathrm{CH}$, Olivier B. Mechanisms underlying tolerance after long-term benzodiazepine use: a future for subtypeselective GABA(A) receptor modulators? Adv Pharmacol Sci 2012;2012:416864.

4. Azar NJ, Lagrange AH, Wang L, Song Y, Abou-Khalil BW. Transient improvement after brief antiepileptic drug withdrawal in the epilepsy monitoring unit: possible relationship to AED tolerance. Epilepsia 2010;51: $811-817$

5. Lee GH, Kim BM, Kang JK, Lee SA. Loss of the initial efficacy of levetiracetam in patients with refractory epilepsy. Seizure 2013;22:185-188.

6. Browne TR, Penry JK. Benzodiazepines in the treatment of epilepsy: a review. Epilepsia 1973;14:277-310.

7. Robertson MM. Current status of the 1,4- and 1,5-benzodiazepines in the treatment of epilepsy: the place of clobazam. Epilepsia 1986;27(suppl 1):S27-S41.

8. Li M, Szabo A, Rosenberg HC. Down-regulation of benzodiazepine binding to alpha 5 subunit-containing gammaaminobutyric acid(A) receptors in tolerant rat brain indicates particular involvement of the hippocampal CA1 region. J Pharmacol Exp Ther 2000;295:689-696.

9. Ramsey-Williams VA, Wu Y, Rosenberg HC. Comparison of anticonvulsant tolerance, crosstolerance, and benzodiazepine receptor binding following chronic treatment with diazepam or midazolam. Pharmacol Biochem Behav 1994; 48:765-772.

10. Riss J, Cloyd J, Gates J, Collins S. Benzodiazepines in epilepsy: pharmacology and pharmacokinetics. Acta Neurol Scand 2008;118:69-86.

11. Gent JP, Bentley M, Feely M, Haigh JR. Benzodiazepine cross-tolerance in mice extends to sodium valproate. Eur J Pharmacol 1986;128:9-15.

12. Scherkl R, Kurudi D, Frey HH. Tolerance to the anticonvulsant effect of clorazepate and clonazepam in mice. Pharmacol Toxicol 1988;62:38-41.

13. Gonsalves SF, Gallager DW. Tolerance to antipentylenetetrazol effects following chronic diazepam. Eur J Pharmacol 1986;121:281-284.

14. Mana MJ, Kim CK, Pinel JP. Tolerance to the anticonvulsant effects of carbamazepine, diazepam, and sodium valproate in kindled rats. Pharmacol Biochem Behav 1992;41: 109-113. 
15. Frey HH, Philippin HP, Scheuler W. Development of tolerance to the anticonvulsant effect of diazepam in dogs. Eur J Pharmacol 1984;104:27-38.

16. ONFI [package insert]. Deerfield, IL: Lundbeck LLC; 2011.

17. Ng YT, Conry JA, Drummond R, Stolle J, Weinberg MA. Randomized, phase III study results of clobazam in LennoxGastaut syndrome. Neurology 2011;77:1473-1481.

18. Conry JA, Ng YT, Kernitsky L, et al. Stable dosages of clobazam for Lennox-Gastaut syndrome are associated with sustained drop-seizure and total-seizure improvements over 3 years. Epilepsia 2014;55:558-567.

19. Conry JA, Ng YT, Paolicchi JM, et al. Clobazam in the treatment of Lennox-Gastaut syndrome. Epilepsia 2009; 50:1158-1166.

20. Clobazam has equivalent efficacy to carbamazepine and phenytoin as monotherapy for childhood epilepsy: Canadian Study Group for Childhood Epilepsy. Epilepsia 1998;39:952-959.

21. Barcs G, Halasz P. Effectiveness and tolerance of clobazam in temporal lobe epilepsy. Acta Neurol Scand 1996; 93:88-93.
22. Lee EH, Yum MS, Choi HW, Ko TS. Long-term use of clobazam in Lennox-Gastaut syndrome: experience in a single tertiary epilepsy center. Clin Neuropharmacol 2013;36:4-7.

23. Hambert O, Petersen I. Clinical, electroencephalographical and neuropharmacological studies in syndromes of progressive myoclonus epilepsy. Acta Neurol Scand 1970;46: 149-186.

24. Hanson RA, Menkes JH. A new anticonvulsant in the management of minor motor seizures. Dev Med Child Neurol 1972;14:3-14.

25. Ng YT, Conry J, Paolicchi J, et al. Long-term safety and efficacy of clobazam for Lennox-Gastaut syndrome: interim results of an open-label extension study. Epilepsy Behav 2012;25:687-694.

26. Brodie MJ, Chung S, Wade A, et al. Clobazam and clonazepam use in epilepsy: results from a UK database incident user cohort study. Epilepsy Res 2016;123:68-74.

27. Jensen HS, Nichol K, Lee D, Ebert B. Clobazam and its active metabolite $N$-desmethylclobazam display significantly greater affinities for $\alpha_{2}$ - versus $\alpha_{1}-G_{A B A}$-receptor complexes. PLoS One 2014;9:e88456.

\section{Help Get the New Congress to Work for Neurology}

The 2016 election may bring about the most sweeping changes in Congress that we have seen in years, if not decades. Join your AAN colleagues at Neurology on the Hill from February 27-28, 2017, and help educate members of Congress so we can address critical health policy problems together. If selected, you will receive training to bring you up-to-date on key issues. Then, we will go to Capitol Hill for face-to-face meetings with congressional members and their staffs. The Academy will cover airfare expenses and hotel accommodations. There is a general registration fee of $\$ 150$, or $\$ 50$ for residents, fellows, and members residing in the Washington, DC, area. Encourage your colleagues to apply as well. Space is limited and fills quickly. Learn more and apply by November 20, 2016, at $A A N$.com/view/2017NOH. 


\section{Neurology}

\section{Deconstructing tolerance with clobazam: Post hoc analyses from an open-label extension study}

Barry E. Gidal, Robert T. Wechsler, Raman Sankar, et al.

Neurology 2016;87;1806-1812 Published Online before print September 28, 2016

DOI 10.1212/WNL.0000000000003253

This information is current as of September 28, 2016

$\begin{array}{ll}\begin{array}{l}\text { Updated Information \& } \\ \text { Services }\end{array} & \begin{array}{l}\text { including high resolution figures, can be found at: } \\ \text { http://n.neurology.org/content/87/17/1806.full }\end{array} \\ \text { Supplementary Material } & \text { Supplementary material can be found at: } \\ \text { http://n.neurology.org/content/suppl/2016/09/28/WNL.0000000000003 } & \text { 253.DC1 } \\ & \text { This article cites } 26 \text { articles, } 2 \text { of which you can access for free at: } \\ & \text { http://n.neurology.org/content/87/17/1806.full\#ref-list-1 } \\ \text { References } & \text { This article, along with others on similar topics, appears in the } \\ \text { following collection(s): } \\ \text { All Epilepsy/Seizures } \\ \text { http://n.neurology.org/cgi/collection/all_epilepsy_seizures } \\ \text { Antiepileptic drugs } \\ \text { http://n.neurology.org/cgi/collection/antiepileptic_drugs } \\ \text { Information about reproducing this article in parts (figures,tables) or in } \\ \text { its entirety can be found online at: } \\ \text { http://www.neurology.org/about/about_the_journal\#permissions } \\ \text { Permissions \& Licensing } & \text { Information about ordering reprints can be found online: } \\ & \text { http://n.neurology.org/subscribers/advertise }\end{array}$

Neurology ${ }^{\circledR}$ is the official journal of the American Academy of Neurology. Published continuously since 1951, it is now a weekly with 48 issues per year. Copyright () 2016 American Academy of Neurology. All rights reserved. Print ISSN: 0028-3878. Online ISSN: 1526-632X.

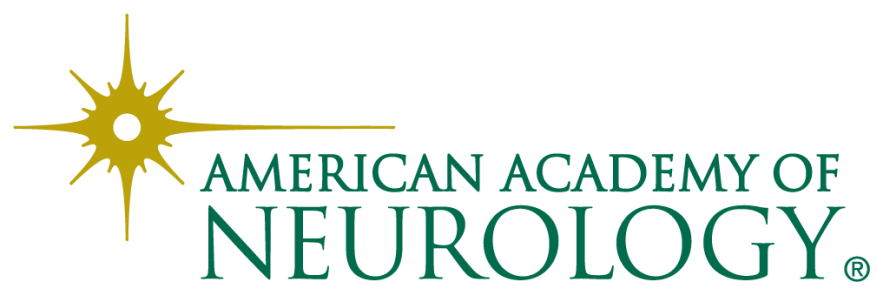

